\title{
Gamma-1-Syntrophin Mediates Trafficking of Gamma-Enolase towards the Plasma Membrane and Enhances Its Neurotrophic Activity
}

\author{
Anja Hafner ${ }^{a}$ Nataša Obermajer ${ }^{a, b}$ Janko Kos ${ }^{a, b}$

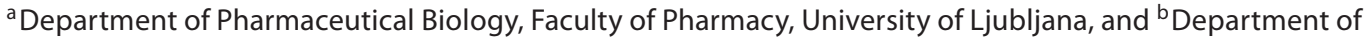 \\ Biotechnology, Jozef Stefan Institute, Ljubljana, Slovenia
}

\section{Key Words}

Gamma-1-syntrophin · Gamma-enolase · Cathepsin X · Intracellular trafficking $\cdot$ Neurotrophic effect

\begin{abstract}
Syntrophins are scaffold proteins that can bind several signaling molecules and localize them to the plasma membrane. We demonstrate here that in neuroblastoma SH-SY5Y cells, brain-specific $\gamma_{1}$-syntrophin binds the neurotrophic factor $\gamma$-enolase through its PDZ domain, and translocates it to the plasma membrane, as shown by immunoprecipitation, surface plasmon resonance, fluorescence colocalization and flow cytometry. Extensive colocalization of $\gamma_{1-}$ syntrophin and $\gamma$-enolase was observed in neurite growth cones in differentiated SH-SY5Y cells. Silencing of the $\gamma_{1}$-syntrophin gene by RNA interference significantly reduced the re-distribution of $\gamma$-enolase to the plasma membrane and impaired its neurotrophic effects. We demonstrated that an intact C-terminal end of $\gamma$-enolase is essential for its $\gamma_{1}$-syntrophin-assisted trafficking. The cleavage of two amino acids at the $\mathrm{C}$-terminal end of $\gamma$-enolase by the carboxypeptidase cathepsin X prevents binding with the $\gamma_{1}$-syntrophin PDZ domain. Collectively, these data demonstrate that $\gamma_{1}$-syn-
\end{abstract}

trophin participates in $\gamma$-enolase translocation towards the plasma membrane, a pre-requisite for its neurotrophic activity. By disrupting this $\gamma_{1}$-syntrophin-guided subcellular distribution, cathepsin $\mathrm{X}$ reduces $\gamma$-enolase-induced neurotrophic signaling.

Copyright $\odot 2011$ S. Karger AG, Basel

\section{Introduction}

Nervous system function depends upon highly specific connections that are formed between neurons during development $[1,2]$. In this process, neurotrophic factors are significant and they have important roles in nerve growth and regeneration, cell differentiation and survival $[3,4]$. Among several proteins, a neurotrophic activity has also been demonstrated for the C-terminal part of $\gamma$-enolase $[5,6]$.

Enolase is a glycolytic enzyme that can form homodimers and heterodimers that are composed of $\alpha, \beta$ and $\gamma$ subunits [7]. In mammalian brain, there are three enolase isoforms: $\alpha \alpha, \alpha \gamma$ and $\gamma \gamma$ [8]. The $\alpha \gamma$ and $\gamma \gamma$ isoforms are also known as neuron-specific enolase: they are primarily found in tissues of the central nervous system, and

\section{KARGER}

Fax +4161306 1234

E-Mail karger@karger.ch

www.karger.com
(C) 2011 S. Karger AG, Basel

$1424-862 \mathrm{X} / 10 / 0184-0246 \$ 26.00 / 0$

Accessible online at:

www.karger.com/nsg
Dr. Janko Kos

Department of Pharmaceutical Biology, Faculty of Pharmacy

University of Ljubljana, Askerceva 7

SI-1000 Ljubljana (Slovenia)

Tel. +38614769604, E-Mail janko.kos@ffa.uni-lj.si 
they have only been localized to neurons and neuroendocrine cells [9]. Previous studies have shown that the C-terminal part of neuron-specific enolase has a neurotrophic activity when it is bound to the plasma membrane of neuronal cells $[5,6,10]$. However, to date, the mechanisms of $\gamma$-enolase translocation and membrane association have remained unknown. The neurotrophic activity of $\gamma$-enolase can be regulated by cathepsin X [11], a carboxypeptidase that is prominently localized in the lysosomal system, although it is also seen scattered through the cytoplasm in almost all cells in the brain [12]. Cathepsin $\mathrm{X}$ has crucial roles in diverse physiological processes, including cell adhesion, phagocytosis and migration, and cytoskeletal rearrangements [13].

The targeting of proteins to specific membrane domains is organised by the scaffold proteins, which are known to enhance the efficiency and specificity of signal transduction [14]. Syntrophins are scaffold proteins with multiple protein interaction domains $[15,16]$. The syntrophin family comprises five structurally related isoforms that are encoded by separate genes: $\alpha_{1}, \beta_{1}, \beta_{2}, \gamma_{1}$ and $\gamma_{2}$. Although all of these isoforms share the same modular domain organization, i.e. two tandem pleckstrin homology domains, a single PDZ domain, and a C-terminal region that is unique to syntrophins, each syntrophin has specific tissue and developmental expression patterns [17, 18]. The $\gamma 1$ isoform of syntrophin is expressed solely in neurons and it binds a unique set of signalling proteins through its PDZ domain $[19,20]$. The C-terminal half of $\gamma_{1}$-syntrophin remains accessible for interactions with members of the dystrophin family of proteins, including dystrophin, utrophin and dystrobrevin [15, 21].

Using immunoprecipitation, surface plasmon resonance, immunofluorescence and flow cytometry, we demonstrate here that $\gamma_{1}$-syntrophin can regulate the subcellular localization of $\gamma$-enolase in neuronal cells, and consequently, its neurotrophic activity. Moreover, we implicate the carboxypeptidase cathepsin X in disruption of the $\gamma_{1}$-syntrophin $/ \gamma$-enolase complex that results in impaired translocation of $\gamma$-enolase towards the plasma membrane and its decreased neurotrophic activity.

\section{Materials and Methods}

\section{Cell Culture and Transfections}

The human neuroblastoma SH-SY5Y cells were obtained from American Type Culture Collection (CRL-2266, Manassas, Va., USA). The cells were grown in Dulbecco's modified Eagle's medium (Sigma, St. Louis, Mo., USA) supplemented with 10\% fetal bovine serum (HyClone, Logan, Utah, USA), 2 mM L-glutamine
(Sigma), $50 \mathrm{U} / \mathrm{ml}$ penicillin and $50 \mu \mathrm{g} / \mathrm{ml}$ streptomycin (Sigma). The cells were maintained at $37^{\circ} \mathrm{C}$ in a humidified atmosphere containing $5 \% \mathrm{CO}_{2}$, and they were grown until $80 \%$ confluence.

The SH-SY5Y cells were then transfected with the pcDNA3/ cathepsin X construct using lipofectamine 2000 (Invitrogen, Carlsbad, Calif., USA), according to the manufacturer protocol. A stable cell line overexpressing cathepsin $\mathrm{X}$ was selected with 400 $\mu \mathrm{g} / \mathrm{ml}$ geneticin (Invitrogen, Gibco, Scotland), with upregulation of cathepsin X activity detected using the cathepsin X-specific, intramolecularly quenched fluorogenic substrate Abz-Phe-GluLys(Dnp)-OH [22]. Cell lysates were prepared in lysis buffer (50 mM sodium acetate, pH 5.5, 1 mM EDTA, $100 \mathrm{~mm} \mathrm{NaCl}, 0.25 \%$ Triton X-100) with protein concentrations determined using the Bradford method [23], using the Coomassie Plus protein assay reagent (Thermo Scientific, Rockford, Ill., USA). An aliquot of $100 \mu \mathrm{g}$ of lysate proteins was incubated at $37^{\circ} \mathrm{C}$, followed by measurement of cathepsin X activity using Abz-Phe-Glu-Lys(Dnp)$\mathrm{OH}$ at a final concentration of $10 \mu \mathrm{M}$. The fluorometric reaction $\left(\lambda_{\text {ex }}=320 \mathrm{~nm}\right.$ and $\lambda_{\text {em }}=420 \mathrm{~nm}$ ) was quantified at $37^{\circ} \mathrm{C}$ on a Safire2 (Tecan, Switzerland) microplate reader. Cell lysates were tested in quadruplicates. Silencing of $\gamma_{1}$-syntrophin was performed with the Stealth ${ }^{\mathrm{TM}}$ RNAi/ $/ 1$-Syn system. The single stranded oligos were (RNA)-GGUAGCUUGUUUGGACCCUCUAUUU and (RNA)-AAAUAGAGGGUCCAAACAAGCUACC (Invitrogen Stealth ${ }^{\mathrm{TM}} \mathrm{RNAi}$; Invitrogen, Carlsbad). SHSY5Y cells were transiently transfected with Stealth RNAi/ $\gamma 1-S y n$ using Lipofectamine 2000 (Invitrogen, Carlsbad), according to the manufacturer protocol. Silencing of $\gamma_{1}$-syntrophin was tested with flow cytometry and Western blotting using $\gamma_{1}$-syntrophin antibody (Santa Cruz, USA). The specificity of this antibody to $\gamma_{1}$-syntrophin was tested by pretreatment with GST- $\gamma_{1}$ PDZ fusion protein (online supplementary figure S1, www. karger.com/doi/10.1159/000324292).

\section{Immunoprecipitation and Western-Blotting}

To prepare cell lysates for analysis of the protein levels, $\mathrm{SH}$ SY5Y cells were washed with PBS, $\mathrm{pH}$ 7.4, and then lysed with 100 $\mu l$ lysis buffer ( $400 \mathrm{~mm}$ phosphate buffer, $\mathrm{pH} 6.0,75 \mathrm{~mm} \mathrm{NaCl}$, $4 \mathrm{mM}$ EDTA-Na $2,0.25 \%$ Triton X-100) including a protease inhibitor cocktail (Thermo Scientific). The cells were incubated on ice for $30 \mathrm{~min}$ and then centrifuged for $10 \mathrm{~min}$ at $10,000 \mathrm{~g}$ and $4^{\circ} \mathrm{C}$. The supernatants were removed and the total protein concentrations were determined by using the Coomassie Plus (Bradford) protein assay reagent (Thermo Scientific). The protein concentrations were adjusted by adding lysis buffer, $\mathrm{pH} 8.0$, to a final concentration of $100 \mu \mathrm{g}$ in $50 \mu \mathrm{l}$. Then $5 \mu \mathrm{g}$ of a mouse anti- $\gamma$-enolase-specific antibody, a mouse anti- $\alpha$-enolase-specific antibody, or a goat anti- $\gamma_{1}$-syntrophin-specific antibody (Santa Cruz Biotechnology, Santa Cruz, Calif., USA) were added. To purify the immune complexes, $50 \mu \mathrm{l}$ of this mixture was added to washed protein A-Sepharose beads (Amersham Pharmacia Biotech AB, Uppsala, Sweden) and mixed overnight at $4^{\circ} \mathrm{C}$. The beads were then washed with binding buffer (0.14 $\mathrm{M}$ phosphate buffer), $\mathrm{pH}$ 8.2 , and the immune complexes eluted by boiling in SDS sample buffer. The samples were resolved by SDS-PAGE and transferred onto nitrocellulose membranes. The membranes were blocked with 5\% skimmed milk powder in PBS, and then incubated with goat anti- $\gamma_{1}$-syntrophin or mouse anti- $\gamma$-enolase monoclonal antibody (Santa Cruz Biotechnology) in 0.05\% Tween in PBS overnight at $4^{\circ} \mathrm{C}$. The blots were washed three times for $10 \mathrm{~min}$ in 
0.05\% Tween in PBS, incubated with the HRP-conjugated secondary antibody (Santa Cruz Biotechnology) for $2 \mathrm{~h}$, and finally washed another three times for $10 \mathrm{~min}$ with $0.05 \%$ Tween in PBS. The immunoreactive bands were visualized after addition of the Super-Signal chemiluminescent substrate (Thermo Scientific). The band intensities from the Western blotting were quantified using the Sygene's GeneTools Software (Sygene, UK), and expressed as relative values to the control lysate.

\section{Peptides}

Synthetic peptides corresponding to the C-terminal 30-amino-acid sequence of human brain $\gamma$-enolase ( $\gamma$-Eno: AKYNQLMRIEEELGDEARFAGHNFRNPSVL), a two-residue-shorter peptide $(\gamma$-Eno $\Delta 432-433$ : AKYNQLMRIEEELGDEARFAGHNFRNPS), and a peptide corresponding to the C-terminal 15amino-acid sequence of human $\alpha$-enolase ( $\alpha$-Eno: KAKFAGRNPRNPLAK), were synthesized by Biosynthesis (Lewisville, Tex., USA).

\section{Expression and Purification of Bacterial Fusion Proteins}

The construct encoding the PDZ domain of $\gamma_{1}$-syntrophin in the plasmid vector pGEX-5X1 was a generous gift from Stephen H. Gee [19]. The fusion protein was purified as described previously [19]. Briefly, BL21( $\lambda$ DE3)pLys competent cells were transformed with pGEX-5X1 and grown in $2 \mathrm{ml} \mathrm{LB}$ medium supplemented with $200 \mu \mathrm{g} / \mathrm{ml}$ ampicillin (LB-Amp) (Sigma) overnight at $37^{\circ} \mathrm{C}$ in a shaking incubator. The bacteria were pelleted by centrifugation and resuspended in $1 \mathrm{ml}$ fresh LB-Amp. Overnight culturing was used to inoculate 1 liter of bacteria in LB-Amp, which was grown at $37^{\circ} \mathrm{C}$ for $2 \mathrm{~h}$ or until the optical density at 600 $\mathrm{nm}$ reached $0.6-1.0$. Protein expression was then induced with $1 \mathrm{~mm}$ isopropyl-1-thio- $\beta$-D-thiogalactopyranoside, and the culture was incubated overnight at $28^{\circ} \mathrm{C}$. The expressed fusion protein was recognized by the GST conjugate and was purified on a glutathione-Sepharose column, according to the manufacturer instructions (Novagen, Madison, Wisc., USA). The fusion protein purity was determined by Coomassie blue staining of SDS-polyacrylamide gels. Protein concentrations were determined by the method of Bradford.

\section{Solid-Phase Binding Assay}

Microtiter plates were coated with $10 \mu \mathrm{g} / \mathrm{ml}$ of the synthetic peptides $\gamma$-Eno, $\gamma$-Eno $\Delta 432-433$ or $\alpha$-Eno, in $0.01 \mathrm{M}$ carbonate/ bicarbonate buffer, $\mathrm{pH} 9.6$, at $4^{\circ} \mathrm{C}$ overnight. After blocking with $3 \%$ BSA in PBS, the expressed and purified GST- $\gamma_{1}$-syntrophin (GST- $\gamma 1 \mathrm{PDZ}$ ) was added at different concentrations, for $4 \mathrm{~h}$ at $37^{\circ} \mathrm{C}$. After washing, a goat anti-GST antibody (Biacore AB, Uppsala, Sweden) was added. Following $2 \mathrm{~h}$ of incubation at $37^{\circ} \mathrm{C}$, the wells were washed and filled with a secondary donkey anti-goat antibody conjugated with HRP. After a further 2-hour incubation at $37^{\circ} \mathrm{C}, 200 \mu \mathrm{g} /$ well of the substrate $3,3^{\prime}, 5,5^{\prime}$ tetramethyl-benzidine was added. After $15 \mathrm{~min}$, the reaction was stopped by adding $50 \mu \mathrm{l} 2 \mathrm{M} \mathrm{H}_{2} \mathrm{SO}_{4}$. Absorbance, which correlated with the binding of GST- $\gamma_{1}$-syntrophin, was measured at $450 \mathrm{~nm}$ using a Safire ${ }_{2}$ microplate reader (Tecan, Switzerland).

\section{Surface Plasmon Resonance}

The relative binding of $\gamma$-enolase $C$-terminal peptides and the $\gamma_{1}$-syntrophin PDZ domain were determined using surface plasmon resonance on a Biacore $\mathrm{X}$ apparatus (Biacore $\mathrm{AB}$ ) at $25^{\circ} \mathrm{C}$.
The synthetic peptides $\gamma$-Eno and $\gamma$-Eno $\Delta 432-433$ were immobilized at a concentration of $50 \mu \mathrm{g} / \mathrm{ml}$ in sodium acetate buffer, $\mathrm{pH}$ 4.5 , at a flow rate of $10 \mu \mathrm{l} / \mathrm{min}$ for $10 \mathrm{~min}$ (290 RU), onto a CM5 chip (Biacore AB, Uppsala, Sweden). A reference surface was prepared for each peptide in the second flow cell by amine coupling activation followed by immediate deactivation. To measure the relative binding, six different concentrations of GST- $\gamma 1$ PDZ fusion protein in PBST buffer (PBS with $0.1 \%$ Tween 20) were injected onto the peptide surfaces for $1 \mathrm{~min}$ at a flow rate $10 \mu \mathrm{l} / \mathrm{min}$. Binding to a reference flow cell was also measured, and used to subtract the non-specific interactions. The association and dissociation rate constants were fitted globally to a two-step binding model using BIA evaluation version 3.2.

\section{Immunofluorescence Colocalization}

SH-SY5Y cells were cultured on glass coverslips at a concentration of $2 \times 10^{4} / \mathrm{ml}$ in 24 -well plates. After $24 \mathrm{~h}$, the cells were fixed with $2 \%$ paraformaldehyde at room temperature for $45 \mathrm{~min}$ and permeabilized with $0.1 \%$ Triton X-100 for 10 min. Nonspecific staining was blocked with 3\% BSA in PBS, pH 7.4 for 30 min. Then the permeabilized cells were incubated with mouse anti- $\gamma$ enolase $(10 \mu \mathrm{g} / \mathrm{ml})$ or goat anti- $\gamma_{1}$-syntrophin $(10 \mu \mathrm{g} / \mathrm{ml})$ (Santa Cruz Biotechnology) antibodies in blocking buffer, for $2 \mathrm{~h}$ at room temperature. Afterwards, the cells were washed with PBS and incubated with the Alexa-labeled secondary antibodies (Molecular Probes, Eugene, Oreg., USA) for an additional $2 \mathrm{~h}$. After washing with PBS, the Prolong Antifade kits (Molecular Probes) were used for mounting the coverslips on glass slides.

For detection of the plasma membrane, the cells were transduced with Organelle Lights ${ }^{\mathrm{TM}}$ Plasma Membrane-GFP (PMGFP; Molecular Probes), following the manufacturer instructions a day before the immunofluorescence staining. The N-terminal end of $\gamma$-enolase was stained using a goat polyclonal antibody raised against a peptide mapping near the N-terminus of $\gamma$-enolase $(5 \mu \mathrm{g} / \mathrm{ml})$ (Santa Cruz Biotechnology).

For actin cytoskeleton localization, F-actin was stained using FITC-labelled phalloidin (500 ng/ml) (Sigma-Aldrich, St. Louis, Mo., USA).

Fluorescence microscopy was performed using a Carl Zeiss LSM 510 confocal microscope (Carl Zeiss, Oberkochen, Germany). Images are presented as single confocal sections and were analyzed using Carl Zeiss LSM image software, version 3.0. The relative colocalization areas, presented in the third quadrant of the images were analyzed for several cells (cell number $\geq 10$ ).

\section{Flow Cytometry Analysis}

SH-SY5Y cells $\left(2 \times 10^{5} / \mathrm{ml}\right)$ were washed with ice-cold PBS and then with $3 \%$ BSA in PBS containing $1 \%$ sodium azide. Nonspecific staining was blocked with 3\% BSA in PBS. Next, the cells were incubated with specific antibodies against the $\mathrm{N}$-terminal end of $\gamma$-enolase $(10 \mu \mathrm{g} / \mathrm{ml})$ for $45 \mathrm{~min}$ at $4^{\circ} \mathrm{C}$. After washing with ice-cold PBS, the cells were fixed with $2 \%$ paraformaladehyde for $15 \mathrm{~min}$ at $4^{\circ} \mathrm{C}$. Afterwards, the cells were incubated with an Alexa Fluor-555-labelled secondary antibody (Molecular Probes) for 45 min at room temperature. After additional washing with PBS, comparative analysis of $\gamma$-enolase on the cell surface was performed on a FACS Calibur machine (BD Biosciences, San Jose, Calif., USA).

For $\alpha$-enolase, $\gamma$-enolase and $\gamma_{1}$-syntrophin staining, cells were first fixed with $2 \%$ paraformaldehyde for $15 \mathrm{~min}$ at room 
temperature and permeabilized with $0.5 \%$ Tween 20 in PBS for 10 min at $4^{\circ} \mathrm{C}$. Afterwards, the cells were incubated with specific antibodies against $\alpha$-enolase, $\gamma$-enolase and $\gamma_{1}$-syntrophin (Santa Cruz Biotechnology) $(10 \mu \mathrm{g} / \mathrm{ml})$, followed by secondary antibody.

\section{Neurite Outgrowth and Neuronal Proliferation Assay}

SH-SY5Y cells were first transfected with Stealth RNAi/ $\gamma 1-$ Syn and nontransfected SH-SY5Y cells were used as the control. The next day ( $24 \mathrm{~h}$ after transfection), the cells were plated into 96 -well plates $\left(2 \times 10^{4}\right.$ cells per well $)$ in the absence or presence of the $\gamma$-enolase peptides, $\gamma$-Eno and $\gamma$-Eno $\Delta 432-433$ at concentration of $100 \mu \mathrm{M}$. After an additional $24 \mathrm{~h}$, the cells showing neurite outgrowth were quantified (at least 100 cells for each group in one experiment, and in three independent experiments). Cells with one or more neurites for which the length was twice the diameter of the cell body were scored as positive. The cells were observed using an Olympus IX 81 motorized inverted microscope (Olympus Biosystems GmbH, Munich, Germany).

In a similar experiment, cell proliferation was determined with the MTS colorimetric assay (Promega, Madison, Wisc., USA). Cell proliferation was determined using equation (1), where $A_{\text {test cells }}$ and $A_{\text {control cells }}$ were the absorbances of formazan measured for the treated and control cells:

$$
\begin{aligned}
& \text { Cell proliferation }(\%)= \\
& \left(A_{\text {test cells }} / A_{\text {control cells }}\right) \times 100
\end{aligned}
$$

\section{Statistical Analysis}

The SPSS PC software (Release 13.0) was used for the statistical analysis of all of the data. The differences between the groups were evaluated using the non-parametric Mann-Whitney test. $\mathrm{p}<0.05$ was considered to be statistically significant.

\section{Results}

\section{Association of $\gamma$-Enolase with $\gamma_{1}$-Syntrophin in}

Neuroblastoma Cells

Scaffold proteins such as the syntrophins may assist to translocate $\gamma$-enolase to the plasma membrane. We detected a complex that formed between $\gamma$-enolase and the scaffold protein $\gamma_{1}$-syntrophin using affinity immunoprecipitation in SH-SY5Y cell lysates. The immunoprecipitates were resolved by SDS-PAGE and immunoblotted. As shown in figure 1a, an antibody to the internal region of $\gamma$-enolase co-immunoprecipitated $\gamma_{1}$-syntrophin from wild-type SH-SY5Y cell lysates. No effects were seen using an antibody to $\alpha$-enolase or with control mouse IgG (fig. 1a), demonstrating the specifity of the association between $\gamma$-enolase and $\gamma_{1}$-syntrophin, although the expression of $\alpha$-enolase in SH-SY5Y cells was 1.7-fold higher over that of $\gamma$-enolase (online suppl. fig. S2). The same pattern was seen in cathepsin-X-overexpressing SH-SY5Y cell lysates with 2.0-fold increased cathepsin $\mathrm{X}$ activity (online suppl. fig. S3); however, here the co-immunoprecipitation was decreased by 7.4 -fold, in comparison to wild-type cells (fig. 1c). In the reciprocal experiment, $\gamma$-enolase was immunoprecipitated using a $\gamma_{1}$-syntrophin antibody as well (fig. $1 b$ ), where in cathepsin-X-overexpressing cells, the co-immunoprecipitation was 3.0-fold lower (fig. 1d). Together, these data suggest that in neuroblastoma cells, $\gamma_{1}$-syntrophin and $\gamma$-enolase can form a stable complex that is less stable in cells with up-regulated cathepsin X.

\section{PDZ Domain of $\gamma_{1}$-Syntrophin Binds to the Preserved \\ $C$-Terminal Peptide of $\gamma$-Enolase}

It is known that PDZ-domain-mediated interactions are based on the recognition of short C-terminal sequences in the targeted membrane proteins [24]. To verify that this represents the binding mode between $\gamma$-enolase and $\gamma_{1}$-syntrophin, solid-phase binding assays were performed. For these we used a soluble glutathioneS-transferase (GST) fusion protein containing the PDZ domain of $\gamma_{1}$-syntrophin (GST- $\gamma 1 \mathrm{PDZ}$ ), and synthethic peptides representing C-terminal end of both $\alpha$-enolase and $\gamma$-enolase, respectively. Of these, the synthetic peptide $\gamma$-Eno corresponded to the entire $\gamma$-enolase $\mathrm{C}$-terminal end, and the two-residues-shorter peptide $\gamma$ Eno $\Delta 432-433$ represented the C-terminal end that results from the gradually cleaving by cathepsin $\mathrm{X}$, meanwhile the synthetic peptide $\alpha$-Eno corresponded to the entire $\alpha$-enolase $\mathrm{C}$-terminal end (fig. 2a). The PDZ domain of $\gamma_{1}$-syntrophin bound to both of C-terminal peptides of $\gamma$-enolase and to the C-terminal peptide of $\alpha$ enolase in a concentration-dependent manner (fig. 2b); however, the binding was significantly lower with the shorter $\gamma$-enolase C-terminal peptide $(\gamma$-Eno $\Delta 432-433)$ and more lower with $\alpha$-enolase $\mathrm{C}$-terminal peptide compared to $\gamma$-Eno peptide.

In addition, the binding of $\gamma$-enolase and $\gamma_{1}$-syntrophin was assessed by surface plasmon resonance analysis. The binding of purified GST- $\gamma 1 \mathrm{PDZ}$ to the immobilised $\gamma$-Eno, the entire C-terminal peptide of $\gamma$-enolase, was concentration dependent (fig. 3a), while the binding of GST- $\gamma 1$ PDZ to the shorter C-terminal peptide of $\gamma$-enolase, $\gamma$-Eno $\Delta 432-433$, was not significantly different from the control (fig. $3 b$ ). The dissociation constant, $\mathrm{K}_{\mathrm{d}}$, calculated from a Scatchard plot was $24.3 \mu \mathrm{M}$ (online suppl. fig. S4). Thus, these data confirm direct interactions of $\gamma$-enolase with $\gamma_{1}$-syntrophin through its PDZ domain, and they stress the importance of the last two amino acids on the $\mathrm{C}$-terminal end of $\gamma$-enolase for binding. 


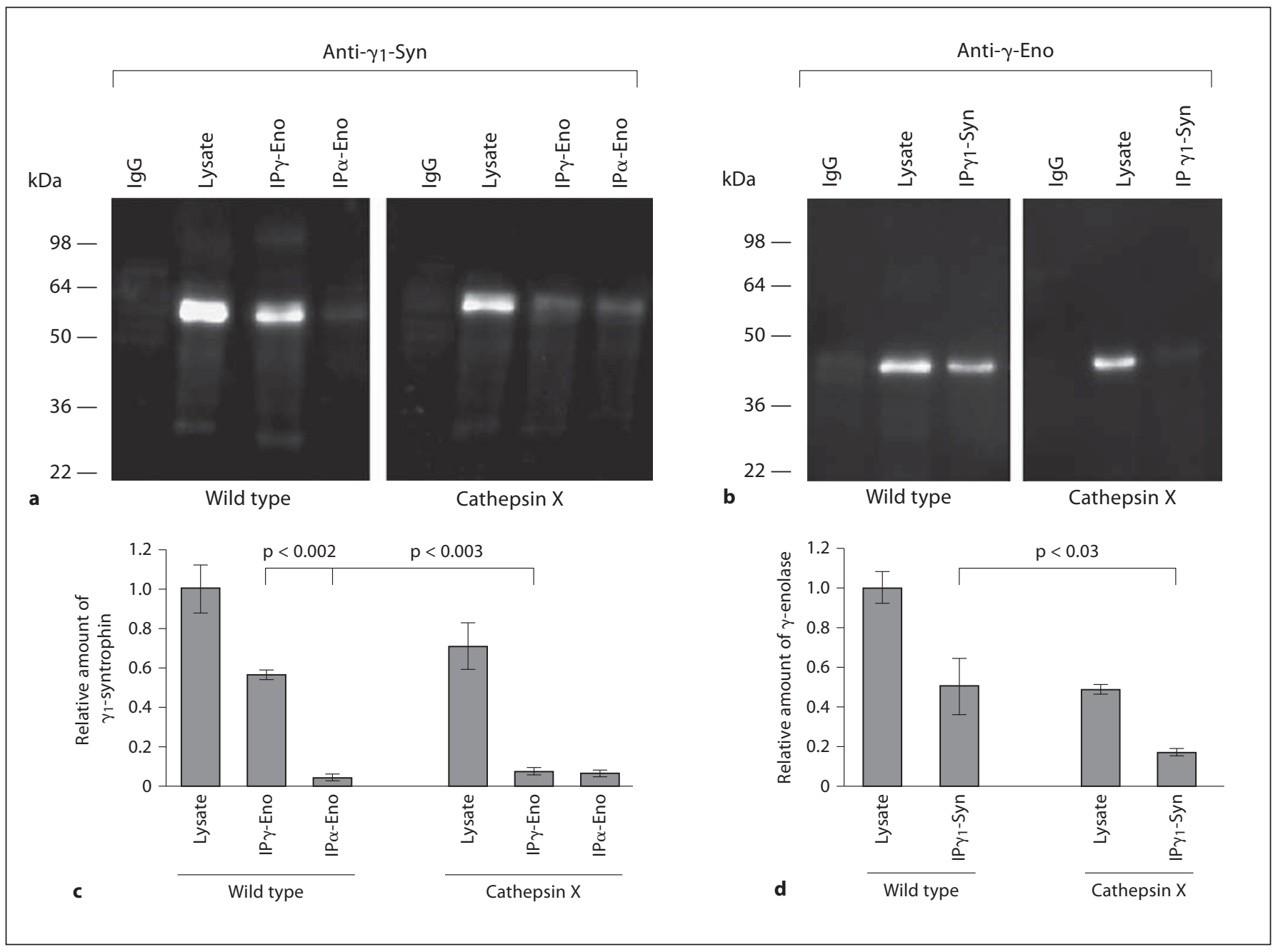

Fig. 1. $\gamma_{1}$-Syntrophin and $\gamma$-enolase form a stable complex in $\mathrm{SH}$ SY5Y cells. a, b Representative reciprocal co-immunoprecipitation of $\gamma_{1}$-syntrophin and $\gamma$-enolase from wild-type and cathepsin-X-overexpressing SH-SY5Y cells. Cells were lysed with Triton $\mathrm{X}-100$ and immunoprecipitated (IP) with either anti- $\boldsymbol{\gamma}$-enolase or anti- $\alpha$-enolase antibodies (a), or with an anti- $\gamma_{1}$-syntrophin antibody (b). The immunoprecipitates were analyzed by Western blotting with anti- $\gamma_{1}$-syntrophin (a) or anti- $\gamma$-enolase (b) antibodies. As negative control, nonspecific mouse IgG was used. c, $\mathbf{d}$ Quantification of data illustrated in $\mathbf{a}$ and $\mathbf{b}$, for the amounts of $\gamma_{1}$-syntrophin and $\gamma$-enolase compared to wild-type SH-SY5Y cell lysate. Data are means \pm SD of at least three independent experiments ( $\mathrm{p}<0.002 ; \mathrm{p}<0.003 ; \mathrm{p}<0.03$; as indicated).
Colocalization of $\gamma_{1}$-Syntrophin and $\gamma$-Enolase in the Peri-Plasma Membrane Region and Neurite Growth Cone of Neuroblastoma Cells

Using confocal immunofluorescence microscopy in wild-type neuroblastoma SH-SY5Y cells, colocalization of $\gamma_{1}$-syntrophin and $\gamma$-enolase was seen in the peri-plasma membrane region and along the neurites (fig. 4a). This colocalization was further examined in SH-SY5Y cells induced to differentiate by serum deprivation. Shortly, after serum deprivation, the neuroblastoma cells flatten and produce filopodia and lamellipodia around their circumference, and therefore gradually extend neurites over the subsequent $16-24 \mathrm{~h}[25,26]$. In SH-SY5Y cells differentiated for $24 \mathrm{~h}, \gamma$-enolase and $\gamma_{1}$-syntrophin were highly concentrated in these early processes of neurite outgrowth (fig. 4b, d). In SH-SY5Y cells transfected with GFP-tagged cathepsin X, the colocalization of $\gamma$ enolase with $\gamma_{1}$-syntrophin was dramatically abolished (fig. 4c, d). 
Fig. 2. Specific interactions of C-terminal peptide of $\gamma$-enolase and $\alpha$-enolase with the PDZ domain of $\gamma_{1}$-syntrophin. a Amino acid sequences of the C-terminal peptides: $\alpha$-Eno, $\gamma$-Eno (entire) and cathepsin$\mathrm{X}$-modified $\gamma$-Eno $\Delta 432-433$. b Binding of GST fusion protein containing the PDZ domain of $\gamma_{1}$-syntrophin (GST- $\gamma 1$ PDZ) to these synthetic peptides, $\alpha$-Eno, $\gamma$-Eno and $\gamma$-Eno $\Delta 432-433$, using the solidphase binding assay. GST- $\gamma 1$ PDZ binds to all peptides in a concentration-dependent manner (b), although binding was 3.3-fold greater with $\gamma$-Eno than $\gamma$-Eno $\Delta 432-433$ and 4.4 -fold greater than $\alpha$-Eno at $1 \mu \mathrm{g} / \mathrm{ml}$ of GST- $\gamma 1$ PDZ. The values are relative to those for the control recombinant GST. Data are means \pm SD of three independent assays ( $p<0.05$; as indicated).

Fig. 3. PDZ domain of $\gamma_{1}$-syntrophin binding to preserved C-terminal peptide of $\gamma$ enolase. a, b Representative association and dissociation curves of PDZ domain of $\gamma_{1}$-syntrophin for binding to C-terminal peptide of $\gamma$-enolase, obtained by surface plasmon resonance. Different concentrations $(0-50 \mu \mathrm{M})$ of the GST- $\gamma 1 \mathrm{PDZ}$ fusion protein were injected onto the surface of a sensor chip coated with the peptides $\gamma$-Eno or $\gamma$-Eno $\Delta 432-433$. Binding of GST- $\gamma 1$ PDZ to the peptides was measured in real time as an increase in resonance units (RU). Binding was stronger at higer concentrations of GST- $\gamma 1 \mathrm{PDZ}$ protein (a), whereas the interaction was abolished when $\gamma$ Eno $\Delta 432-433$ peptide was immobilized on the cell surface (b).

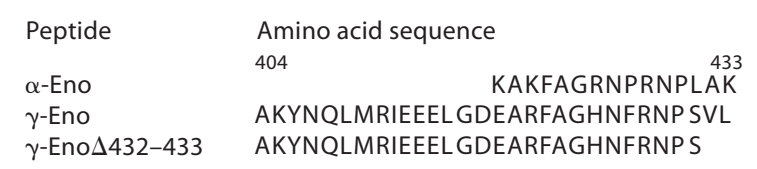

a $\gamma$-Eno $\Delta 432-433$ AKYNQLMRIEEELGDEARFAGHNFRNPSVL

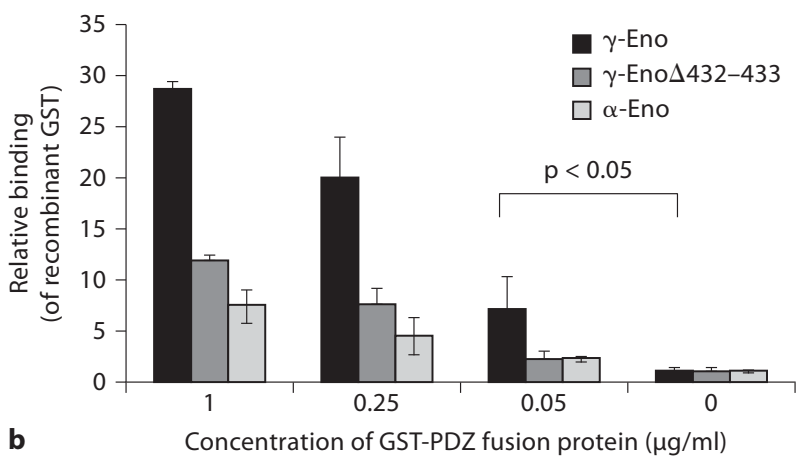

Concentration of GST-PDZ fusion protein $(\mu \mathrm{g} / \mathrm{ml})$
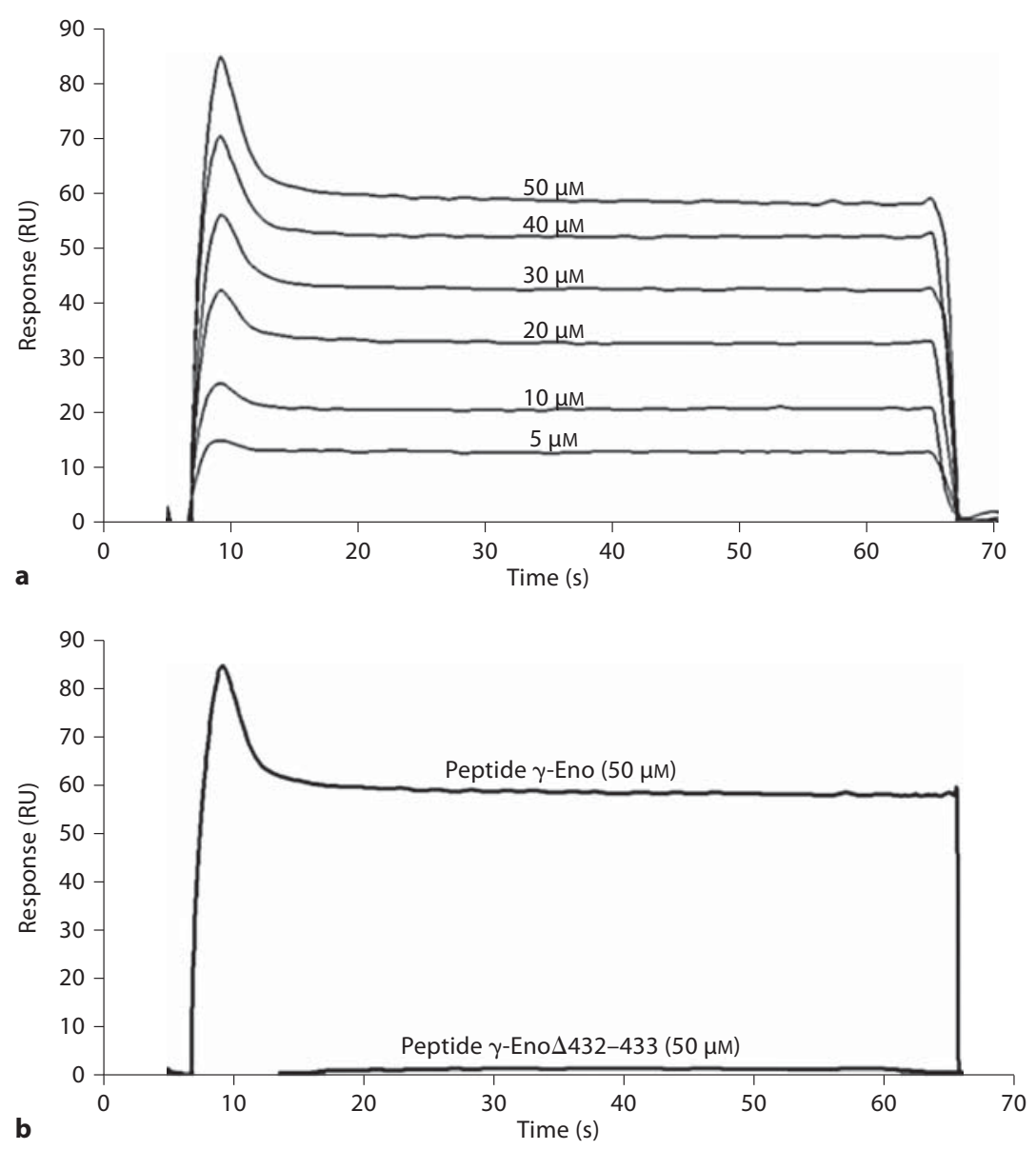

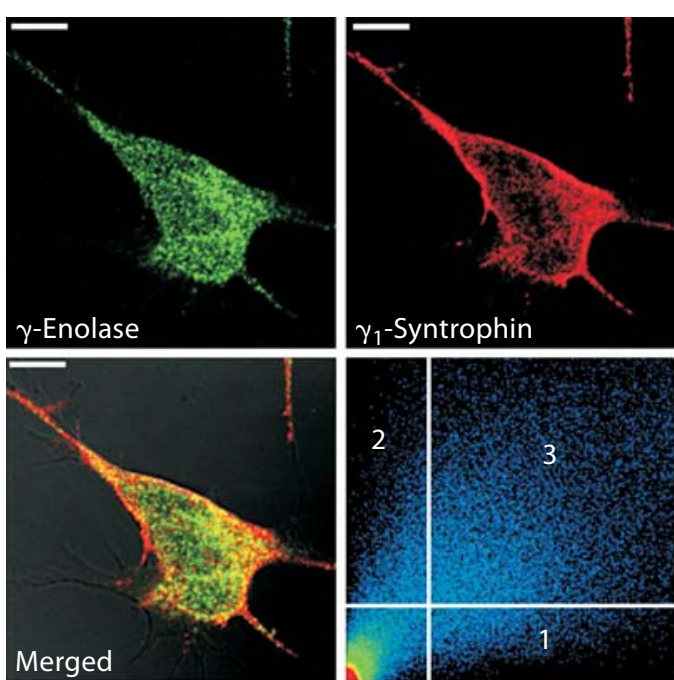

a

Wild type
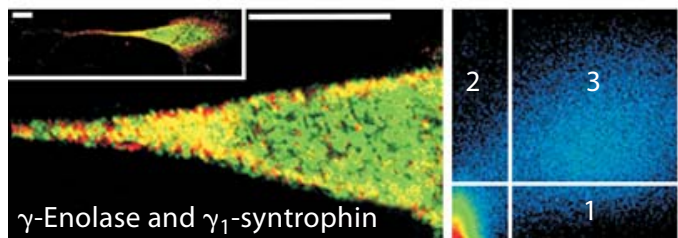

b

Serum deprivation
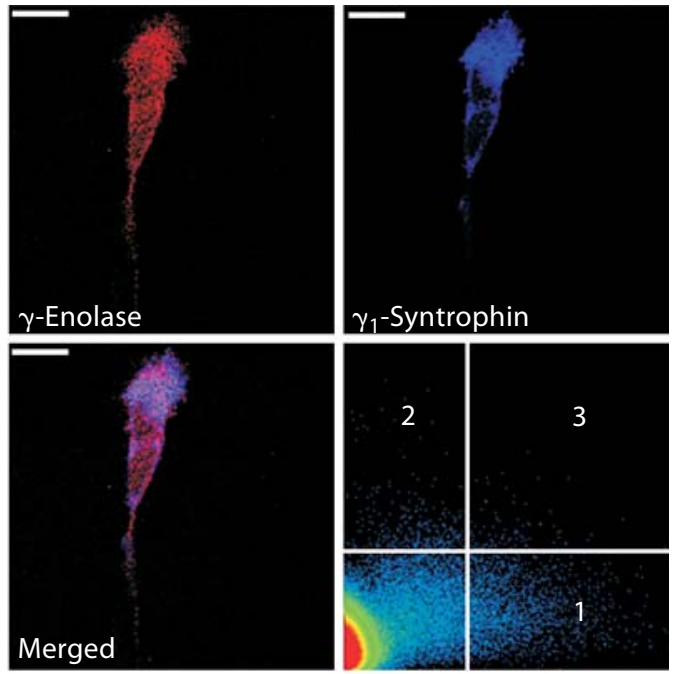

c

pcDNA3/cathepsin X

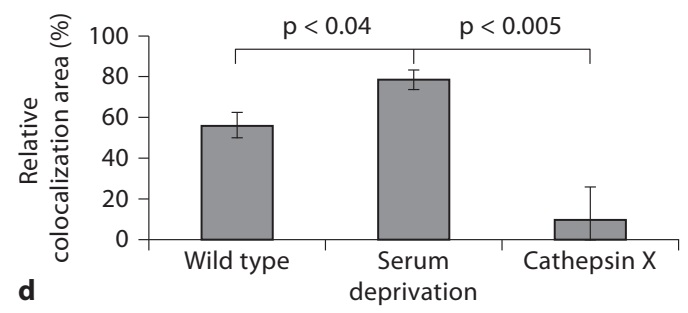

Fig. 4. Subcellular colocalization of $\gamma_{1}$-syntrophin and $\gamma$-enolase. a-c Representative images of colocalization of $\gamma$-enolase and $\gamma_{1^{-}}$ syntrophin in SH-SY5Y cells, as analyzed by confocal microscopy. The proteins were visualized by immunofluorescent staining using antibodies to $\gamma$-enolase and $\gamma_{1}$-syntrophin, followed by Alexa Fluor 488 (green)- and Alexa Fluor 633 (red)-conjugated secondary antibodies, respectively (a, b), or Alexa Fluor 555 (red)- and Alexa Fluor 633 (blue)-conjugated secondary antibodies, respectively (c). a Colocalization in wild-type SH-SY5Y cells was mainly at the plasma membrane, as shown by the pixels above the threshold in both channels on the contour plot (third quadrant). b Colocalization in SH-SY5Y cells differentiated for 24 h by serum deprivation was higher at the neurite growth cone. c Decreased colocalization in cathepsin-X-overexpressing cells. Scale bars $=10 \mu \mathrm{m}$. d Colocalization quantification of the data illustrated in $\mathbf{a}-\mathbf{c}$ (cell numbers $\geq 10)$. Data are means $\pm \mathrm{SD}(\mathrm{p}<0.04$; $\mathrm{p}<0.005$; as indicated).

binding to $\gamma_{1}$-syntrophin, we decreased the expression of $\gamma_{1}$-syntrophin using a $\gamma_{1}$-syntrophin-specific small-interfering (si) RNA, the Stealth RNAi/ $\gamma 1-$ Syn system. Reduced $\gamma_{1}$-syntrophin protein level for $68 \% 24 \mathrm{~h}$ or for $60 \% 48 \mathrm{~h}$ after transfection, respectively, as confirmed by flow cytometry and Western blotting (online suppl. fig. S5) abolished the $\gamma$-enolase colocalization with the plasma membrane marker (fig. 5b) in comparison to intact neuroblastoma cells (fig. 5a, c). Additionally, the surface of neuroblastoma cells was examined for the presence of $\gamma$-enolase by flow cytometry. A single-cell suspension of wild-type SH-SY5Y cells, cells with overexpressed ca- 


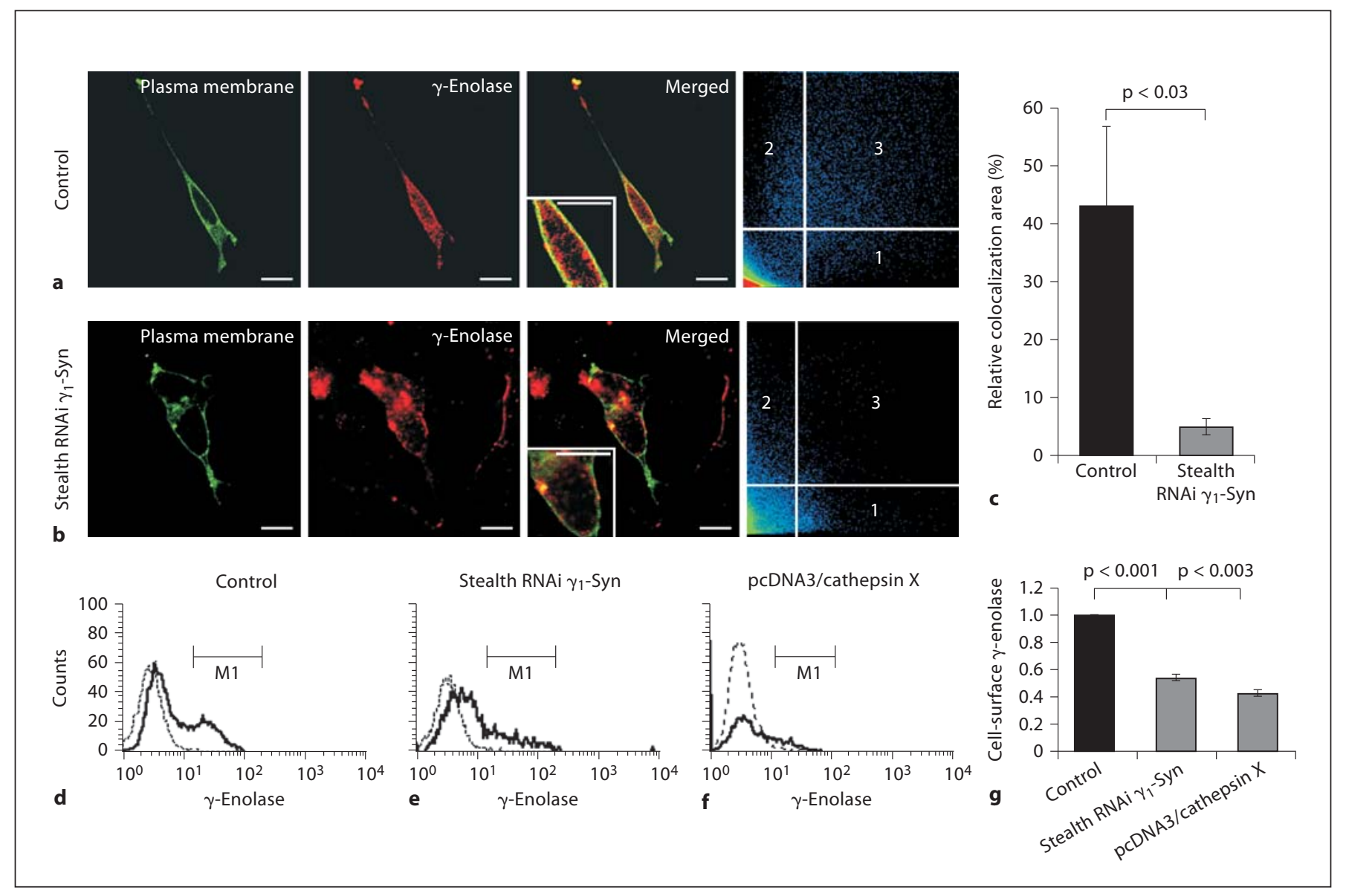

Fig. 5. Silencing of $\gamma_{1}$-syntrophin expression abolishes $\gamma$-enolase translocation towards the plasma membrane. a, b SH-SY5Y cells were transfected with $\gamma_{1}$-syntrophin-specific siRNA $24 \mathrm{~h}$ before transduction with Organelle Lights ${ }^{\mathrm{TM}}$ PM-GFP for direct expression of autofluorescent protein that is localized in the plasma membrane. $\gamma$-Enolase antibody was added, and then labeled with an Alexa Fluor 555 secondary antibody. In the representative images, the colocalization of $\gamma$-enolase with the plasma membrane marker was seen (a), which was abolished in cells with downregu- lated $\gamma_{1}$-syntrophin (b). c Quantification of the relative colocalization areas in $\mathbf{a}$ and $\mathbf{b}$ (cell numbers $\geq 10$ ). Data are means \pm $\mathrm{SD}$ ( $\mathrm{p}<0.03$, as indicated). Scale bar $=10 \mu \mathrm{m}$. $\mathbf{d}-\mathbf{f}$ Representative flow cytometric analysis of nonpermeabilized SH-SY5Y cells transfected with $\gamma_{1}$-syntrophin-specific siRNA or pcDNA3/cathepsin X. Broken thin line represents an isotype control and thick solid line a plasma membrane localization of $\gamma$-enolase, respectively. Quantitative data are means \pm SD of at least three independent experiments $(\mathbf{g})(\mathrm{p}<0.001 ; \mathrm{p}<0.003$, as indicated $)$. thepsin $\mathrm{X}$ and cells with reduced $\gamma_{1}$-syntrophin was stained with the antibody to the N-terminal end of $\gamma$-enolase under nonpermeabilized conditions. As seen in figure $5 \mathrm{~d}$ and $5 \mathrm{e}$, the signal for the $\gamma$-enolase was 1.9fold greater, compared to cells with reduced expression of $\gamma_{1}$-syntrophin (fig. $5 \mathrm{~g}$ ). The nonspecific IgG as a control provided no positive staining (data not shown). In cathepsin-X-overexpressing SH-SY5Y cells, the signal for the $\gamma$-enolase also decreased, as shown in figure $5 f$, and was 2.3-fold lower compared to wild-type cells (fig. $5 \mathrm{~g}$ ).
Effects of $\gamma_{1}$-Syntrophin Silencing on $\gamma$-Enolase-

Mediated Cell Proliferation, Neurite Outgrowth and

Actin-Based Cytoskeleton Remodeling

Next, we analyzed the effects of silencing the $\gamma_{1}$-syntrophin gene with the Stealth RNAi $/ \gamma_{1}$-Syn system, on $\gamma$-enolase-induced neurite outgrowth and cell proliferation. The morphology of SH-SY5Y cells was examined $24 \mathrm{~h}$ after exposure to a synthetic peptide that corresponded to $\gamma$ Eno, the entire $\gamma$-enolase $\mathrm{C}$-terminal end and to shorter peptide, $\gamma$-Eno $\Delta 432-433$. Treatment with $\gamma$-Eno peptide increased the number of cells with neurite elongation, as 
Fig. 6. Neurotrophic effects of $\gamma$-enolase are regulated by $\gamma_{1}$-syntrophin expression. a Inhibition of $\gamma_{1}$-syntrophin expression with transient transfection of SH-SY5Y cells with Stealth RNAi/ $\gamma 1-S y n$. After transfection, cells were cultured in the presence or absence of the $\gamma$-enolase peptides ( $\gamma$-Eno and $\gamma$-Eno $\Delta 432-433 ; 100$ $\mu \mathrm{M})$ and after an additional $24 \mathrm{~h}$ the frequency of neurite outgrowth was determined. $\mathbf{b}$ Representative DIC images of $\boldsymbol{\gamma}$ Eno-treated nontransfected (left panel) and Stealth RNAi/ $\gamma 1-$ Syn transfected SHSY5Y cells (right panel) are shown. Scale bars $=50 \mu \mathrm{m}$. c SH-SY5Y cells were treated as in a, and after $24 \mathrm{~h}$ the cell proliferation was assessed by the MTS assay. Data are means $\pm \mathrm{SD}$ of two independent experiments $(\mathrm{p}<0.005 ; \mathrm{p}<0.01 ; \mathrm{p}<0.0001 ; \mathrm{p}<$ 0.05 ; as indicated).

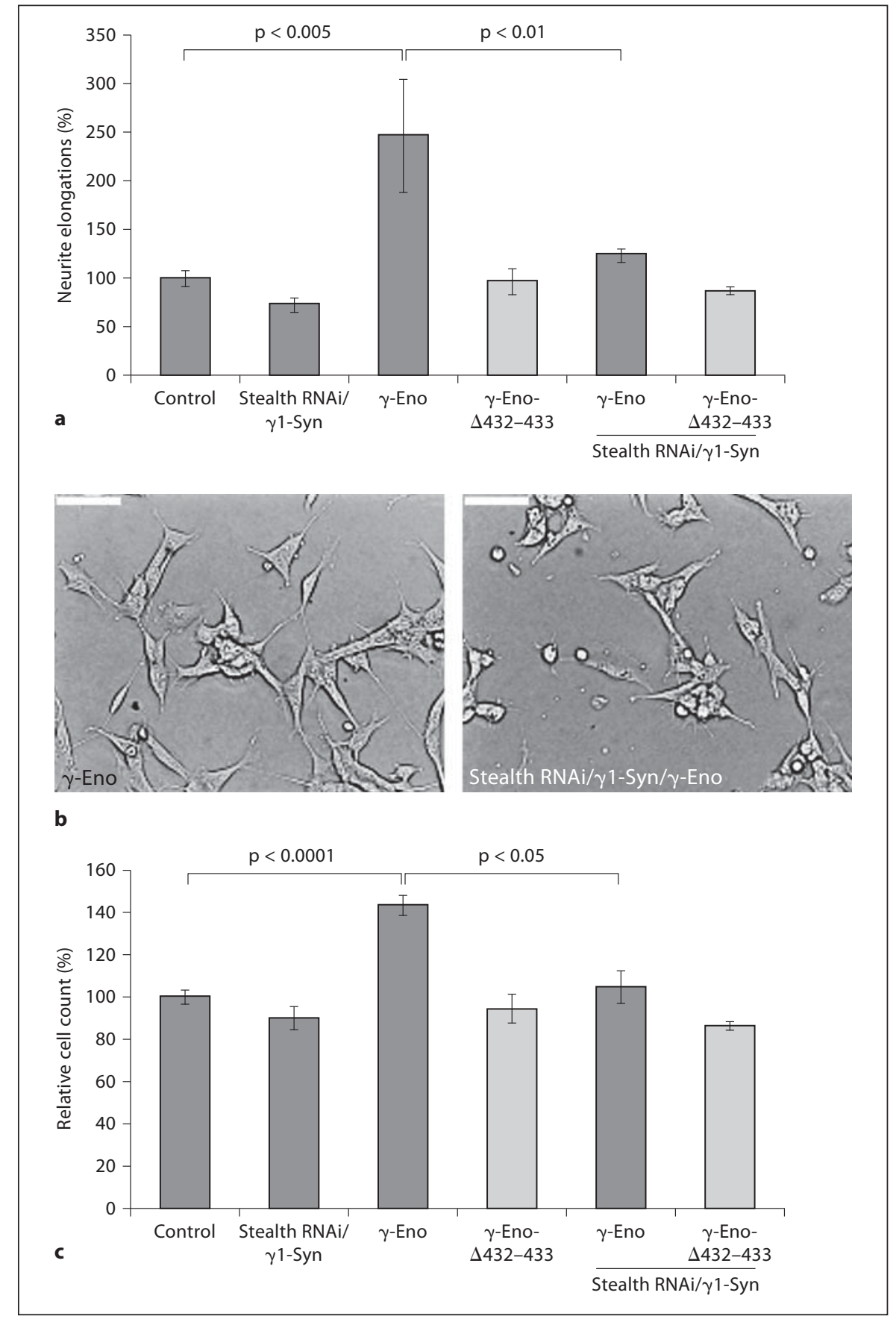

compared to untreated cells, while the $\gamma$-enolase-mediated neuritogenic effects were abolished in $\gamma_{1}$-syntrophin down-regulated SH-SY5Y cells (fig. 6a). SH-SY5Y cells with reduced protein level of $\gamma_{1}$-syntrophin appeared to undergo little if any $\gamma$-enolase-mediated neurite outgrowth, as seen in figure $6 \mathrm{~b}$. At the same time, in these siRNA-transfected SH-SY5Y cells $\gamma$-enolase-mediated cell proliferation was decreased by 1.4 -fold in comparison to nontransfected SH-SY5Y cells (fig. 6c). The same experiments were performed for peptide $\gamma$-Eno $\Delta 432-433$ represented the C-terminal end that lacks last two amino acids. Nontransfected cells treated with the $\gamma$-Eno $\Delta 432-433$ did not undergo neurite outgrowth (fig. 6a) as well as $\gamma$ Eno $\Delta 432-433$ peptide had no significant proliferative ef- 

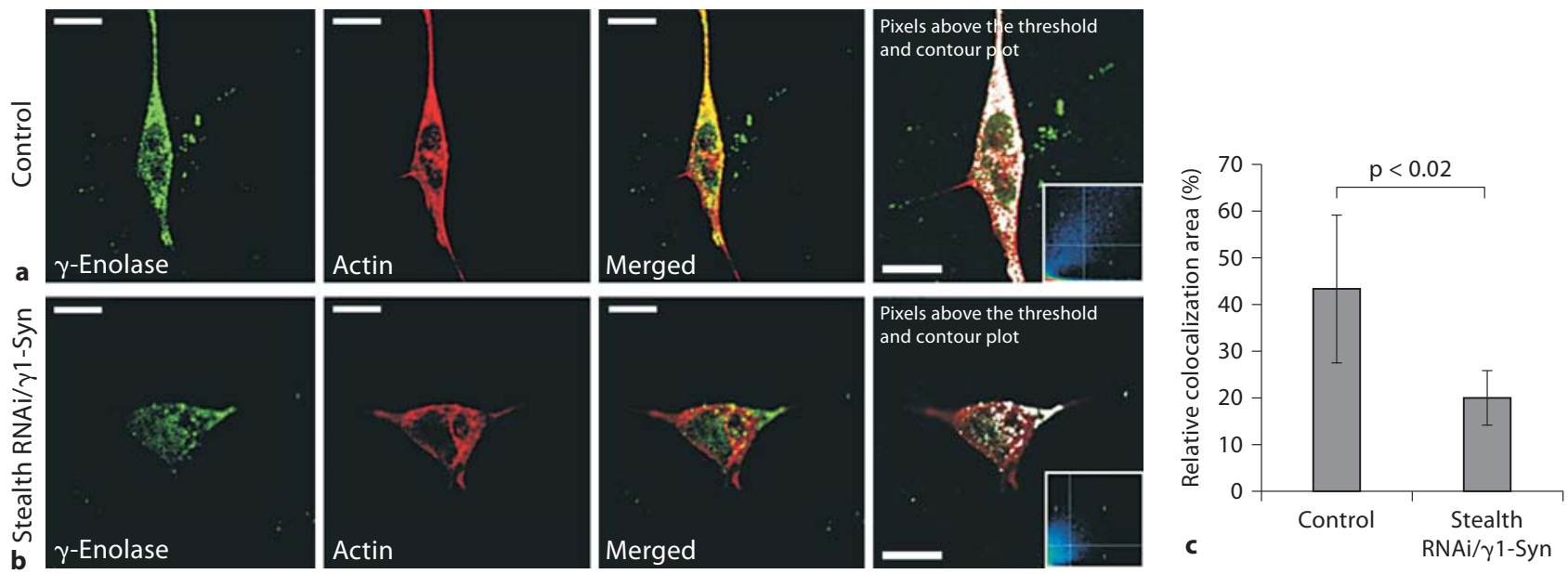

Fig. 7. Subcellular colocalization of $\gamma$-enolase and actin filaments depends on $\gamma_{1}$-syntrophin expression. $\mathbf{a}, \mathbf{b}$ Representative images of nontransfected SH-SY5Y cells or cells transfected with Stealth RNAi/ $\gamma 1-S y n$ and labeled for immunofluorescence detection of $\gamma$-enolase (green) using a mouse monoclonal antibody followed by Alexa Fluor 488-conjugated secondary antibody. Actin filaments (red) were labeled with TRITC-phalloidin. Strong colocal- ization of $\gamma$-enolase and actin filaments in non-transfected cells (control), as shown on the merged image (yellow) and by the pixels above the thresholds (a). Lower colocalization was evident in transfected cells with downexpression of $\gamma_{1}$-syntrophin (b). Scale bars $=10 \mu \mathrm{m}$. c Quantification of relative colocalization areas of $\gamma$-enolase and actin filaments in $\mathbf{a}$ and $\mathbf{b}$ (cell numbers $\geq 10$ ). Data are means $\pm \mathrm{SD}(\mathrm{p}<0.02$, as indicated $)$. fect on SH-SY5Y cells (fig. 6c). The same results were observed in SH-SY5Y cells with reduced $\gamma_{1}$-syntrophin expression, meaning that the last two amino acids are essential for $\gamma$-enolase-mediated neurotrophic effects.

For neurite outgrowth and for active intracellular transport, dynamic remodeling of the actin-based cytoskeleton is a prerequisite $[1,27]$. High colocalization of $\gamma$-enolase with actin filaments was observed (fig. 7a). When the expression of $\gamma_{1}$-syntrophin was decreased using the Stealth RNAi $/ \gamma_{1}$-Syn system, there were seen lower levels of $\gamma$-enolase colocalization with actin filaments (fig. 7b, c). Taken together, these results demonstrate an important role of $\gamma_{1}$-syntrophin in trafficking of $\gamma$-enolase and consequently its neurotrophic activity.

\section{Discussion}

The present study highlights a key role for $\gamma_{1}$-syntrophin in the regulation of the subcellular distribution and neurotrophic function of $\gamma$-enolase. The preserved C-terminus of $\gamma$-enolase, which contains a consensus PDZbinding motif, is necessary for its interaction with the
PDZ domain of $\gamma_{1}$-syntrophin. In this way, $\gamma_{1}$-syntrophin aids in the translocation of $\gamma$-enolase towards the plasma membrane, where it can then exert its neurotrophic activity. The formation of this signaling complex is abolished by cathepsin $\mathrm{X}$, through its modulation of the $\mathrm{C}$-terminal end of $\gamma$-enolase.

Enolase is a glycolytic enzyme that is generally viewed as a soluble cytosolic protein, although several other functions associated with its plasma membrane localization have been reported $[28,29]$. For example, $\alpha$-enolase can serve as a receptor for the binding of plasminogen to the cell surface, through its exposed C-terminal lysine residues [30]. The neuron-specific enolase has been found in rat brain synapses [31], with half of the amount present in these synapses seen as membrane associated [32]. Here, we demonstrate that $\gamma$-enolase is indeed present in neuroblastoma SH-SY5Y cells and that it can be associated with the plasma membrane. Although our results do not directly confirm its membrane integration, the latter may occur via hydrophobic domain in its $\mathrm{N}$-terminal region (32-AAVPSGASTGIY-43) [33] similar to what has been suggested for the hydrophobic domain of $\alpha$-enolase (33-AAVPSGASTGIY-44) [34]. 
The C-terminal end of $\gamma$-enolase contains a consensus PDZ-binding motif (431-SVL-433), but not the C-terminal end of $\alpha$-enolase (431-LAK-433), that appears to be involved in its cellular redistribution. There are several PDZ-domain-containing proteins that are involved in intracellular signaling pathway events, including localization to the cell membrane $[14,35]$. PDZ domains preferentially bind peptides that terminate in hydrophobic amino acids and with a Ser, Thr or Tyr at the -2 position from the C-terminus [36]. Alessi et al. [20] showed that $\gamma_{1}$-syntrophin PDZ domain binds a unique set of signaling proteins that are different from those recognized by other syntrophins. We have shown here that in wild-type SH-SY5Y cells, $\gamma_{1}$-syntrophin forms a stable complex with $\gamma$-enolase; at the same time, $\alpha$-enolase does not copurify with $\gamma_{1}$-syntrophin. Although both isoforms show high amino-acid sequence homology (82\%) [5], there is a significant difference in C-terminal regions [33], as $\alpha$ enolase lacks the SVL C-terminal consensus PDZ-binding motif. Although we cannot exclude the possibility that the translocation of $\gamma$-enolase is due to interactions with PDZ-containing proteins (scaffold proteins) other than $\gamma_{1}$-syntrophin, our data clearly show a direct interaction between the PDZ domain of $\gamma_{1}$-syntrophin and the $\mathrm{C}$-terminal end of $\gamma$-enolase. As the localization of $\gamma$-enolase in the periplasma membrane region was diminished after silencing the $\gamma_{1}$-syntrophin gene further, this supports the interaction of $\gamma_{1}$-syntrophin with $\gamma$ enolase and its role in intracellular trafficking.

It has been proposed that a 30 -amino acid C-terminal region of $\gamma$-enolase (A404-L433) promotes neurotrophic and neuroprotective effects [5]. As shown by solid-phase binding assays and surface plasmon resonance, the preserved C-terminus of $\gamma$-enolase (A404-L433) is also necessary for its interactions with the PDZ domain of $\gamma_{1}$-syntrophin. The peptide deduced from the C-terminal of $\gamma$-enolase binds to the PDZ domain in the micromolar range $\left(\mathrm{K}_{\mathrm{d}}, 24.3 \mu \mathrm{M}\right)$; however, a lower affinity for PDZ-mediated interactions might be more suited for the dynamic assembly of PDZ-domain protein complexes [37]. On the contrary, as the product of cathepsin X cleavage of two $\gamma$-enolase $\mathrm{C}$-terminal amino acid residues [11], a peptide shorter by two amino acids (A404-S431) showed significantly reduced binding to the PDZ domain of $\gamma_{1}$-syntrophin. Similarly, a peptide, corresponding to C-terminal end of $\alpha$-enolase also exhibited weak binding to the PDZ domain. Collectively, the interactions mediated through the PDZ domain of $\gamma_{1}$-syntrophin might be important for the subcellular distribution of $\gamma$-enolase, and this regulation can be modulated by cathepsin $\mathrm{X}$.
We favor the idea that $\gamma_{1}$-syntrophin serves to sequester the full-length $\gamma$-enolase from the cytosol towards the plasma membrane. The colocalization of $\gamma_{1}$-syntrophin and $\gamma$-enolase mainly at the periplasma membrane region and along neurites in wild-type SH-SY5Y cells supports this idea. On the other hand, in cathepsin-X-overexpressing SH-SY5Y cells, the colocalization of $\gamma$-enolase and $\gamma_{1}$-syntrophin was abolished. Additionally, co-immunoprecipitation of $\gamma$-enolase and $\gamma_{1}$-syntrophin from cathepsin X-overexpressing cells was less prominent than it was from wild-type cells. This is thus in agreement with previous reports from our group, where we have shown that the $\mathrm{C}$-terminal of $\gamma$-enolase is gradually shortened by two amino acids, V432 and L433, through cleavage by cathepsin X [11], therefore removing the PDZ-binding motif.

The precise subcellular location of this $\gamma$-enolase processing by cathepsin $\mathrm{X}$ is not clear yet. In neuronal cells, cathepsin X was found in the cytoplasm [12] and can thus interact with its target, $\gamma$-enolase. On the other hand, cathepsin $\mathrm{X}$ was also shown to colocalize with $\gamma$-enolase in perimembrane regions where proteolytic cleavage can also occur [11]. In our previous study, we showed that cathepsin X abolished the neurotrophic activity of $\gamma$-enolase and impaired neuritogenesis, linking these effects to the proteolytic cleavage of the C-terminal region of $\gamma$-enolase, and consequently with the elimination of its neurotrophic function [11]. In the present study, we have provided another mechanism for the impairment of $\gamma$-enolase neurotrophic function, i.e. cathepsin X can regulate this process by eliminating the PDZ-binding motif in the $\mathrm{C}$-terminal region of $\gamma$-enolase, preventing the binding to $\gamma_{1}$-syntrophin and the translocation towards the plasma membrane.

To our knowledge, this is the first report proposing a mechanism for $\gamma$-enolase translocation in neuroblastoma cells. These data are also consistent with the study of Yakubchyk et al. [38], who showed regulation of neurite outgrowth through PDZ-mediated recruitment of diacylglycerol kinase- $\delta$ (DGK- $\delta$ ). They demonstrated that the C-terminal PDZ-binding motif of DGK- $\delta$ is necessary for neurite outgrowth after its translocation to the plasma membrane by $\gamma_{1}$-syntrophin. For neurite outgrowth dynamic remodeling of the actin-based cytoskeleton is fundamental $[1,39]$. Consistent with a potential role of $\gamma_{1}$-syntrophin in actin reorganization, we have also shown that $\gamma$-enolase colocalizes with actin filaments in the perimembrane region, while this interaction was altered in the absence of $\gamma_{1}$-syntrophin. The C-terminal region of syntrophins can bind to members of the dystro- 
phin family [15], which, at the same time, are known to bind directly to actin [21,40]. Therefore, syntrophins might provide a link between $\gamma$-enolase and actin cytoskeleton remodeling.

In conclusion, we have identified a mechanism of translocation of $\gamma$-enolase towards the plasma membrane in neuroblastoma cells. This arises through the interaction between the PDZ domain of the scaffold protein $\gamma_{1}$-syntrophin with the C-terminal region of $\gamma$-enolase. We propose that this activity is required for $\gamma$-enolasemediated neurotrophic effects. Within this framework, increased activity of cathepsin $\mathrm{X}$ interferes with the formation of this translocation complex thus preventing $\gamma$-enolase from exerting its neurotrophic functions, such as enhancement of cell proliferation and induction of neurite outgrowth.

\section{Acknowledgements}

We thank Dr. Bojan Doljak for technical assistance with the surface plasmon resonance experiments, which were performed in the Infrastructural Centre for Surface Plasmon Resonance, at the Department of Biology, University of Ljubljana, Slovenia. This study was supported by a grant from the Research Agency of the Republic of Slovenia (grant P4-0127 to J.K.) and partially by a Women in Science UNESCO award (N.O.).

\section{References}

1 Luo L: Actin cytoskeleton regulation in neuronal morphogenesis and structural plasticity. Annu Rev Cell Dev Biol 2002;18:601635.

2 Nikolic M: The role of Rho GTPases and associated kinases in regulating neurite outgrowth. Int J Biochem Cell Biol 2002;34:731745 .

3 Nagtegaal ID, Lakke EA, Marani E: Trophic and tropic factors in the development of the central nervous system. Arch Physiol Biochem 1998;106:161-202.

-4 Jin E, Nosaka K, Sano M: NGF-dependent formation of ruffles in PC12D cells requires a different pathway from that for neurite outgrowth. Neurochem Int 2007;51:216-226.

5 Hattori T, Ohsawa K, Mizuno Y, Kato K, Kohsaka S: Synthetic peptide corresponding to 30 amino acids of the $\mathrm{C}$-terminal of neuron-specific enolase promotes survival of neocortical neurons in culture. Biochem Biophys Res Commun 1994;202:25-30.

-6 Hattori T, Takei N, Mizuno Y, Kato K, Kohsaka S: Neurotrophic and neuroprotective effects of neuron-specific enolase on cultured neurons from embryonic rat brain Neurosci Res 1995;21:191-198.

-7 Rider CC, Taylor CB: Enolase isoenzymes in rat tissues. Biochim Biophys Acta 1974;365: 285-300.

8 Fletcher L, Rider CC, Taylor CB: Enolase isoenzymes. III. Chromatography and immunological characteristic of rat brain enolase. Biochim Biophys Acta 1976;452:245-252.

-9 Schmechel DE, Marangos PJ, Martin BM, Winfield S, Burkhart DS, Roses AD, Ginns EI: Localization of neuron-specific enolase (NSE) mRNA in human brain. Neurosci Lett 1987;76:233-238

10 Takei N, Kondo J, Nagaike K, Ohsawa K, Kato K, Kohsaka S: Neuronal survival factor from bovine brain is identical to neuron-specific enolase. J Neurochem 1991;57:11781184.
11 Obermajer N, Doljak B, Jamnik P, Fonovič UP, Kos J: Cathepsin X cleaves the C-terminal dipeptide of alpha- and gamma-enolase and impairs survival and neuritogenesis of neuronal cells. Int J Biochem Cell Biol 2009; 41:1685-1696.

12 Wendt W, Zhu XR, Lübbert H, Stichel CC Differential expression of cathepsin $\mathrm{X}$ in ag ing and pathological central nervous system of mice. Exp Neurol 2007;204:525-540.

13 Kos J, Jevnikar Z, Obermajer N: The role of cathepsin $\mathrm{X}$ in cell signaling. Cell Adh Migr 2009;3:164-166.

14 Burack WR, Shaw AS: Signal transduction: hanging on a scaffold. Curr Opin Cell Biol 2000;12:211-216.

15 Albrecht DE, Froehner SC: Syntrophins and dystrobrevins: defining the dystrophin scaffold at synapses. Neurosignals 2002;11:123129.

16 Kachinsky AM, Froehner SC, Milgram SL: A PDZ-containing scaffold related to the dystrophin complex at the basolateral membrane of epithelial cells. J Cell Biol 1999;145: 391-402.

-17 Ahn AH, Freener CA, Gussoni E, Yoshida M, Ozawa E, Kunkel LM: The three human syntrophin genes are expressed in diverse tissues, have distinct chromosomal locations, and each bind to dystrophin and its relatives. J Biol Chem 1996;271:2724-2730.

18 Piluso G, Mirabella M, Ricci E, Belsito A, Abbondanza C, Servidei S, Puca AA, Tonali P, Puca GA, Nigro V: Gamma1- and gamma2syntrophins, two novel dystrophin-binding proteins localized in neuronal cells. J Biol Chem 2000;275:15851-15860.

19 Hogan A, Shepherd L, Chabot J, Quenneville S, Prescott SM, Topham MK, Gee SH: Interaction of gammal-syntrophin with diacylglycerol kinase-zeta: regulation of nuclear localization by PDZ interactions. J Biol Chem 2001;276:26526-26533.
20 Alessi A, Bragg AD, Percival JM, Yoo J, Albrecht DE, Froehner SC, Adams ME: Gamma-syntrophin scaffolding is spatially and functionally distinct from that of the alpha/ beta syntrophins. Exp Cell Res 2006;312: 3084-3095.

21 Allikian MJ, McNally EM: Processing and assembly of the dystrophin glycoprotein complex. Traffic 2007;8:177-183.

-22 Puzer L, Cotrin SS, Cezari MH, Hirata IY, Juliano MA, Stefe I, Turk D, Turk B, Juliano L, Carmona AK: Recombinant human cathepsin $\mathrm{X}$ is a carboxymonopeptidase only: a comparison with cathepsins B and L. Biol Chem 2005;386:1191-1195.

23 Bradford MM: A rapid and sensitive method for the quantitation of microgram quantities of protein utilizing the principle of proteindye binding. Anal Biochem 1976;72:248254.

24 Gee SH, Quenneville S, Lombardo CR, Chabot J: Single amino-acid substitutions alter the specificity and affinity of PDZ domains for their ligands. Biochemistry 2000; 39:14638-14646.

25 Sarner S, Kozma R, Ahmed S, Lim L: Phosphatidylinositol 3-kinase, Cdc42, and Racl act downstream of Ras in integrin-dependent neurite outgrowth in N1E-115 neuroblastoma cells. Mol Cell Biol 2000;20:158172 .

26 Ishii T, Satoh E, Nishimura M: Integrinlinked kinase controls neurite outgrowth in N1E-115 neuroblastoma cells. J Biol Chem 2001;276:42994-43003.

27 Geissler H, Ullmann R, Sodati T: The tail domain of myosin $\mathrm{M}$ catalyses nucleotide exchange on Racl GTPases and can induce actin-driven surface protrusions. Traffic 2000; 1:399-410.

28 Uyeda K: Interactions of glycolytic enzymes with cellular membranes. Curr Top Cell Regul 1992;33:31-46. 
29 Nakajima K, Hamanoue M, Takemoto N, Hattori T, Kato K, Kohsaka S: Plasminogen binds specifically to alpha-enolase on rat neuronal plasma membrane. J Neurochem 1994;63:2048-2057.

30 Redlitz A, Fowler BJ, Plow EF, Miles LA: The role of an enolase-related molecule in plasminogen binding to cells. Eur J Biochem 1995;227:407-415.

31 Lim L, Hall C, Leung T, Mahadevan L, Whatley S: Neurone-specific enolase and creatine phosphokinase are protein components of rat brain synaptic plasma membranes. J Neurochem 1983;41:1177-1182.

- 32 Ueta H, Nagasawa H, Oyabu-Manabe Y, Toida K, Ishimura K, Hori H: Localization of enolase in synaptic plasma membrane as an alphagamma heterodimer in rat brain. Neurosci Res 2004;48:379-386.
33 McAleese SM, Dunbar B, Fothergill JE, Hinks LJ, Day IN: Complete amino-acid sequence of the neurone-specific gamma isozyme of enolase (NSE) from human brain and comparison with the non-neuronal alpha form (NNE). Eur J Biochem 1988;178: 413-417.

34 Butterfiled AD, Brade Lange ML: Multifunctional roles of enolase in Alzheimer's disease brain: beyond altered glucose metabolism. J Neurochem 2009;111:915-933.

35 Ponting CP, Phillips C, Davies KE, Blake DJ: PDZ domains: targeting signaling molecules to sub-membranous sites. Bioessays 1997;19: 469-479.

36 Songyang Z, Fanning AS, Fu C, Xu J, Marfatia SM, Chishti AH, Crompton A, Chan AC, Anderson JM, Cantley LC: Recognition of unique carboxyl-terminal motifs by distinct PDZ domains. Science 1997;275:73-77.
37 Tochio H, Mok YK, Zhang Q, Kan HM, Bredt DS, Zhang M: Formation of nNOS/PSD-95 PDZ dimer requires a preformed beta-finger structure from the nNOS PDZ domain. J Mol Biol 2000;303:359-370.

38 Yakubchyk Y, Abramovici H, Maillet JC, Daher E, Obagi C, Parks RJ, Topham MK, Gee $\mathrm{SH}$ : Regulation of neurite outgrowth in N1E115 cells through PDZ-mediated recruitment of diacylglycerol kinase zeta. Mol Cell Biol 2005;25:7289-7302.

39 Luo L: Rho GTPases in neuronal morphogenesis. Nat Rev Neurosci 2000;1:173-180.

40 Keep NH: Structural comparison of actin binding in utrophin and dystrophin. Neurol Sci 2000;21:S929-S937. 